\title{
Die opskrifte van die profeteboeke II
}

\author{
JP Oberholzer
}

\begin{abstract}
This is a continuation of a survey of the headings of the prophetic books. In this article special attention is given to the headings in Jeremiah, the possible motives for their formation and the consequences to be inferred in view of the evaluation of the prophet's words during and after his lifetime.
\end{abstract}

Die voordrag wat ek in Julie 1972 voor die Ou-Testamentiese Werkgemeenskap oor dié onderwerp gehou het, is eers ses jaar later gepubliseer, op ' $n$ geleentheid toe daar vir bywerking nie tyd was nie (Oberholzer [1978]). Sover ek my kan herinner, het Van Selms destyds enkele vriendelike opmerkings oor die voordrag gemaak, maar tog laat blyk dat hy ten opsigte van die opskrif van Jeremia 'n eie opvatting het. Dit het duidelik geword toe sy Jeremia-kommentaar in dieselfde jaar verskyn het (Van Selms 1972). Soos sy Genesis in dieselfde reeks, in sy Jeremia 'n sprankelende produk vol oorspronlikhede. Die hipotese wat hy in Excurs 1 oor die verhouding tussen die Septuagint en die Masoretiese teks van Jeremia stel, het in die twaalf jaar wat sindsdien verloop het, nie die aandag ontvang wat dit verdien nie, hoewel dit van ingrypende belang is vir die Inleidingsprobleme van die boek Jeremia. As 'n teregwysing aan myself vertolk ek sy opmerking dat dit metodies onjuis is om die afwykende lesing van die Septuagint in Jeremia 1:1 geïsoleerd te bekyk sonder rekenskap van die geheel van die verhouding tussen die Septuagint en die Masoretiese teks. Wat dié verhouding betref, is Van Selms se bevinding dat ons te doen het met twee resensies van die boek Jeremia, een waarvan verteenwoordig word deur die Septuagint en een deur die Masoretiese teks. Sy verklaring vir die bestaan van die twee resensies is heel prakties: Jeremia se sekretaris, Baruk, het die boekrol met die profeet se uitsprake, soos hy dit met verloop van tyd opgeteken het, na Egipte saamgeneem toe hy en Jeremia daarheen saamgevat is deur die vlugtende Judeërs (Jer 40:1-43:7). In Egipte het Baruk nog enkele uitsprake bygeskryf (43:8-45:5), en later, hetsy op bevel van die profeet, hetsy na sy dood, 'n afskrif van die boek vervaardig vir die Joodse ballinge in Babilonië. Die oorspronklike aantekeninge was die kladskrif, en die afskrif wat vir die ballinge in 
Babilonië vervaardig is, was die definitiewe uitgawe van die boek. Hierin het Baruk, soos gewoonlik met die verwerking van 'n kladskrif gebeur, betreklik vry met sy oorspronklike aantekeninge omgegaan. Die afskrif was bedoel vir voorlesing by die godsdienstige byeenkomste van die ballinge in Babilonië en is vir dié doel saamgestel. Baruk het egter nie sy kladskrif vernietig nie. Dit het in Egipte gebly en daar die grondslag van die Septuagint geword. Teen hierdie agtergrond verklaar Van Selms dan die verskil tussen die opskrifte van onderskeidelik die Septuagint-resensie en die Masoretiese resensie van die boek Jeremia. Die Septuagint se weergawe is die oorspronklike en was bedoel as opskrif van hoofstuk 1. Baruk het vir die Babiloniese kopié egter ' $n$ ander opskrif gekies om aan te sluit by Jeremia 1:3 wat oor die hele reeks openbarings praat wat Jeremia te beurt geval het tot met die val van Jerusalem. Dié opskrif was dan ook bedoel as 'n opskrif van die hele boek.

Enkele vrae dring hulleself op na aanleiding van hierdie bevinding van Van Selms. Die eerste is dié oor die Hebreeuse oorspronklike van die Septuagint se opskrif. Dit is opvallend dat die perikoopopskrifte in Jeremia ' $n$ betreklik vaste vorm het en dat die Septuagint-weergawe daarvan 'n ewe vaste vorm vertoon, met uitsondering van slegs enkele gevalle. Ons het in die Hebreeus naamlik die vorm haddābär sǎser hāy $\bar{a}$ 'el-yirm yāhü mẹ'et yhwh in $7: 1 ; 11: 1 ; 18: 1 ; 21: 1 ; 30: 1 ; 32: 1 ; 34: 1,8 ; 35: 1$ en 40:1. Daarnaas is daar die vorm haddābār ${ }^{\star}$ šer hāya ${ }^{c}$ al-yirm ${ }^{c}$ yâh $\bar{u}^{c} a l$ in 25:1 en 'n soortgelyke vorm in 44:1, maar daar met 'el in plaas van 'al in albei gevalle, en dan ook nog haddābār ${ }^{\star x}$ šer dibber yhwh'el-yirm yāhū hannābi in 46:13 en haddābār ${ }^{x a} \overline{s e r}$ dibber yhwh 'el-bābel 'el-'eres kaśdìm $b^{e}$ yad yirm yāh $\bar{u} h a n n a \bar{b} \vec{P}$ in 50:1. Die Septuagint-weergawe van hierdie opskrifte verloop soos volg: in $7: 1$ ontbreek dit; in $11: 1 ; 18: 1 ; 21: 1 ; 30: 1$ (LXX 37:1); 32:1 (LXX 39:1); 34:1,8 (LXX 41:1,8); 35:1 (LXX 42:1) en 40:1 ( $\mathrm{XXX} 47: 1$ ) lui dit ho lógos ho genómenos parà kuriou pròs leremian, met in vyf gevalle 'n omruiling van parà kuriou en pròs leremian; in 25:1 lui die Septuagint-weergawe ho lógos ho genómenos pròs leremian epi, in $44: 1$ (LXX 51:1) ho lógos ho genómenos pròs leremian hapasin tô̂s ...; in $46: 13$ (LXX 26:13) het die Septuagint die haddābār òf nie in sy Hebreeuse teks gehad nie ò dit genegeer, want hy het ha elálēsen kúrios en cheiri leremiou, en in 50:1 (LXX 27:1) volg die Septuagint heeltemal 'n eie weg met lógos kuriou hon elálēsen epi Babulōna. Hiernaas is ook nog in ag te neem die opskrif waarmee die versameling uitsprake teen ander volke

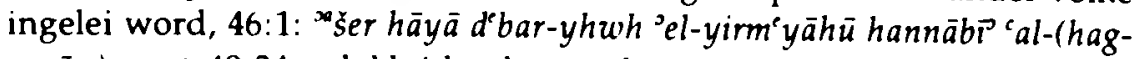
goyim), met 49:34 gelykluidend, wat deur die Septuagint (25:14) ver- 
vang word met 'n eie opskrif ha eprofēteusen leremias epì tà ethnë. Van Selms het kennis geneem van die verskille, maar ' $n$ formulering soos dié in die vorige sin is in stryd met sy opvatting. Nie die Septuagint het ' $n$ opskrif vervang nie, want die Septuagint-resensie was immers die oorspronklike kladskrif. Daarom: Baruk het telkens veranderinge aangebring. By 7:1 het hy onthuu wat hy later in hoofstuk 26 oor dieselfde optrede van Jeremia geskryf het en die opskrif in ooreenstemming daarmee gebring. By 50:1 het Baruk die opskrif gewysig om duidelik te maak dat dit nie net om die hoofstad gaan nie, maar om die hele land en tewens om te verseker dat wat volg, van Jeremia afkomstig is. Enkele problematiese aspekte word egter nie deur Van Selms behandel nie. Om terug te keer na die vraag oor die Hebreeuse oorspronklike van die Septuagint-opskrif in 1:1, as dit 'n perikoopopskrif was wat aanvanklik net op die eerste hoofstuk betrekking gehad het, sou ons kon verwag dat dit gelykluidend met die ander perikoopopskrifte in die boek sou gewees het: ho lógos ho genómenos .... Maar in werklikheid het ons hier 'n heel besondere opskrif wat nie alleen in Jeremia nie, maar in die hele profetekorpus uniek is, naamlik tò rēma tô theô hò egéneto epi. Slegs in Jesaja $14: 28 ; 15: 1 ; 17: 1 ; 22: 1$ en $23: 1$ kom rēma in opskrifte voor, en daar is dit 'n weergawe van maśśá $\bar{a}^{3}$. In opskrifte word

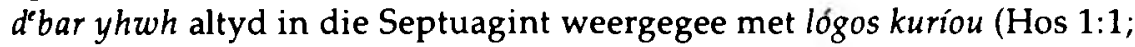
Mig 1:1; Joël 1:1; Sef 1:1). Omdat ook in Jeremia 1:2 theô in plaas van kuriou in die Septuagint voorkom en omdat in Jeremia 6:10 d'bar yhwh wel met tò réma kuriou weergegee word, al is dit dan nie in 'n opskrif nie, sal ons uiteindelik tog moet bevind dat daar in die Hebreeuse teks $d^{\text {b bar yhwh }}{ }^{x}$ ser hāy $\bar{a}{ }^{\circ} e l$ gestaan het. Maar dan was dit nie 'n perikoopopskrif wat net op die eerste hoofstuk betrekking gehad het nie, maar wel 'n opskrif van die hele boek, wat net soos in die ander gevalle waar dié opskrif voorkom, 'n ouer opskrif vervang het. Minstens dan wat hierdie opskrif in 1:1 betref, lyk dit of die Septuagint ' $n$ resensie verteenwoordig wat nie aan die Masoretiese resensie voorafgegaan het nie, maar daarop gevolg het. Die ouer opskrif was dibrẹ yirm ${ }^{e} y \bar{a} h \bar{u}$, en eers 'n herwaardering van die profeet se uitsprake het gelei tot die Septuagint-resensie se opskrif (Oberholzer [1978] $78 \mathrm{vv}$ ).

'n Tweede probleem is dié van Jeremia 50:1 (LXX 27:1). In die masoretiese resensie het ons hier te doen met 'n perikoopopskrif wat uitgebrei is om 'n volwaardige boekopskrif te vorm. Die uitbreiding b'yad yirm ${ }^{e} \bar{a} h \bar{u}$ hannābl herinner aan Haggai $1: 1 ; 2: 1$ en Maleagi 1:1, en aan die Septuagint-opskrif in 26:13 (Mas 46:13), maar daarnaas ook aan die geykte uitdrukking wat so dikwels in die Koningsboeke gebruik word 
in verwysings na profete-uitsprake, en elders in verwysings na uitsprake deur Moses: $k a^{s a}$ šer dibber yhwh beyad. Dit is opmerklik dat ook die Septuagint-opskrif in Jeremia 50:1 (LXX 27:1) 'n volwaardige boekopskrif is. Die Hebreeuse oorspronklike was waarskynlik debar yhwh ${ }^{a x}$ Šer dibber 'al bābel. Uit 51:59-64 weet ons dat 50:2-51:58 inderdaad 'n selfstandige boek was. Weer eens kom dit voor of die Septuagint-opskrif jonger is as dié in die Masoretiese resensie. Elders in Jeremia is die Masoretiese opskrif immers in die styl van die perikoopopskrifte en is slegs uitgebrei om ' $n$ boekopskrif te vorm, terwyl die Septuagint-opskrif ' $n$ definitiewe redaksionele ingryping verteenwoordig in die styl van die opskrifte van Hosea, Joël, Miga en Sefanja, almal boeke wat tydens of na die ballingskap hulle huidige opskrifte gekry het. Hierdie opskrifte skyn tuis te wees in die deuteronomistiese gedagtewêreld. Dat Baruk in dié gedagtewêreld kon gedeel het en selfs daartoe kon bygedra het, is baie waarskynlik. 'n Verandering vanaf ' $n d^{2} b a r$ yhwh-opskrif na 'n haddābār-opskrif lyk egter minder waarskynlik.

Dit is nou ook die geleentheid om te kyk na die ander haddābāropskrif wat as 'n boekopskrif sou kon geld, naamlik Jesaja 2:1. In die

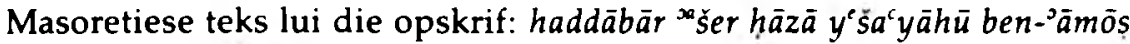
'al y'hūda wirüušălāim. So 'n formule word geheel en al deur die relatiefsin gedra, en is steeds as geheel gevorm. Die voorkoms van $h z h$ hier is uniek. Elders vind ons in Numeri 22:38 haddābār ${ }^{\star s ̌ s ̌ r ~ y a ̄ s i m ~}{ }^{*}$ lōhìm bepi, in 2 Samuel 7:25; Jeremia 46:13; 50:1 haddābār ${ }^{x a}$ šer dbr (yhwh) en in Jeremia $7: 1 ; 11: 1 ; 18: 1 ; 21: 1 ; 25: 1 ; 30: 1 ; 32: 1 ; 34: 1,8 ; 35: 1 ; 40: 1 ; 44: 1$ haddābār ${ }^{2 a}$ šer hāyā 'ol ('al). Onmiskenbaar verteenwoordig die laasgenoemde formule 'n teologies diep deurdagte beskouing. Die geheimenis van die openbaringsontvangs word hier volkome geëerbiedig, en die afgrensing teenoor valse aansprake is tot ' $n$ finale stadium gevoer. Terwyl in die profetiese uitsprake self $h z h$ nie gebruik word om die eie openbaringsbelewenis aan te dui nie, maar wel dié van 'valse' profete (vgl bv Jes 30:10; Eseg 13:6; Sag 10:2), is die profete self wel aangedui as sieners, soos onder andere blyk uit die opskrifte in Jesaja $1: 1 ; 2: 1 ; 13: 1$; Amos 1:1 en Miga 1:1. Dit kan net beteken dat op ' $n$ bepaalde stadium toe hierdie boeke van opskrifte voorsien is (in die geval van Miga nie die finale opskrif nie - Van der Woude 1976: 13) die profetewoorde nog nie skerp onderskei is van dié van 'sieners' of 'valse' profete nie. Tegelyk is dit duidelik dat dergelike opskrifte nie van die profete self of van persone wat as hulle geesgenote of dissipels beskou sou kon word, afkomstig kan wees nie. Die vraag dring hom dus op: Hoe en waar is profetiese uitsprake en versamelings van uitsprake bewaar en metter- 
tyd aan redaksionele prosesse onderwerp? Die gangbare teorie oor dissipelkringe lyk minder en minder aanvaarbaar. In die geval van die profete tot voor Jeremia lyk dit of die tempel die aangewese plek was vir die bewaring van sulke geskrifte en dat tempelpersoneel diegene sou wees wat besonderhede oor profetiese optredes opgeteken en geleidelik redigerend opgetree het. Dit is immers by die tempel dat die toets van Deuteronomium 18: 15-22 aangelê moes gewees het en waar profetewoorde mettertyd as gesaghebbend erken is. Daarmee is die bestaan van geesgenote, aanhangers en selfs dissipels van profete nie sonder meer uit te skakel nie, solank hulle egter nie gesien word as buite en los van die 'amptelike' godsdienstige gemeenskap wat sy sentrum in die kultus gehad het nie. Indien dit nie geskied nie, word dit moeilik om te begryp hoe 'n profeteboek wat binne 'n dissipelkring sy beslag gekry het, op 'n gegewe stadium amptelike erkenning en gesag gekry het. En dit skyn wel seker te wees dat die uitsprake van die profete van die agste eeu reeds in die volgende eeu soveel gesag gehad het dat die profete van die sewende eeu op allerlei wyses by hulle kon aansluit. 'n Sprekende voorbeeld daarvan, afgesien van talle inhoudelike aansluitings, is die verwysing na Miga in Jeremia 26:17-19. Die betrokke hoofstuk in Jeremia skilder die beroering wat in die geledere van die priesters en profete ontstaan het oor die uitsprake van 'n profeet wat so radikaal van die tradisionele teologie afgewyk het. In die geval van Jeremia staan ons dan ook by 'n keerpunt in die profeteoorlewering, en teen dié agtergrond lyk dit aanneemlik dat sy uitsprake nie by die tempel bewaar sou gebly het nie. Tog lyk dit of nie alleen die mondelinge oorlewering oor sy uitsprake nie, maar selfs dele van sy boek in opgetekende vorm aan die priester Esegiël, bekend was op 'n stadium toe Esegiël reeds in ballingskap en Jeremia nog in Jerusalem was (Zimmerli 1969: 67). Zimmerli wys daarop dat Esegiël se gebruik en uitbouing van die beeld van die eet van die Jahwe se woorde by 'n 'konfessie' van Jeremia aansluit (Jer 15:10-21) wat waarskynlik nie in die openbaar uitgespreek is nie, maar in die mees vertroude kring oorgelewer en daar opgeteken is. Alles tesame is die bewyse wat Zimmerli en ander aanvaar vir 'n besonder noukeurige kennis van Jeremiawoorde by Esegiël, nie so klinkklaar dat daar nie oor geredeneer kan word nie. Van Selms wys egter self daarop dat Esegiël meermale by Jeremia-woorde aansluit, en noem $6: 17 ; 30: 9$ en $31: 29$, almal uit die jeugtyd van Jeremia (Van Selms 1974a: 79). Wat 30-31 betref, spreek alles daarvoor dat hierdie 'troosskrywe' wat deur Van Selms as 'n sterk vermeerderde heruitgawe van 'n vroeër geskrif beskou word, wel ook 
na die Judese ballinge in Babel gestuur is, miskien saam met die briewe in 29 en waarskynlik in 594-593 v C. Hierdie dokumente alleen is egter nie genoegsame verklaring vir Esegiël se kennis van Jeremia-woorde nie. Dit kan aanvaar word dat die ballinge van 597 nie sonder ' $n$ versameling boekrolle Jerusalem verlaat het nie, en dat wat te redde was in die katastrofe van 586, saam is na Babel toe. Ook al sou Van Selms se hipotese aanvaar word, sou dit waarskynlik slegs beteken dat die 'netskrif' wat Baruk vir gebruik in Babel gereedgemaak het, die eerste volledige Jeremia-boek in Babel geword het.

Met dié voorlopige opmerkings is nog nie 'n begin gemaak met 'n werklik kritiese beoordeling van ons ontslape leermeester se indringende beskouing oor die teks- en oorleweringsgeskiedenis van die Jeremia-boek nie. Daarvoor is soveel aandag en meer nodig as wat hy self daaraan gegee het. Hier gaan dit vir ons om die opskrifte, maar tot dusver het ' $n$ beskouing van die opskrifte tog 'n paar vrae laat ontstaan wat in ag geneem moet word by alle ander getuienis. Ons bepaal dus vervolgens ons aandag by die opskrifte in die Jeremia-boek, en dan eerstens by die perikoopopskrifte, dit is dié opskrifte wat nie bedoel was as opskrifte van 'n volledige boek nie, maar slegs van die uitspraak of uitsprake wat direk daarop volg. Veral die relatiefsin in dié opskrifte

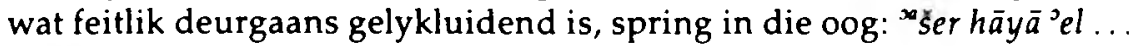
mẹ et yhwh. Daarnaas vind ons in 46:13 en in die Boekopskrif 50:1 'n ander relatiefsin: ${ }^{x}$ šer dibber yhwh. Die vraag dring hom onmiddellik op waarom binne dieselfde boek nie dieselfde formule dwarsdeur gebruik is nie. Die onderskeid bestaan ook in die Septuagint. Ongelukkig gaan Van Selms by die onderskeid verby. Waar hy wel 'n nota by die opskrifte maak, skryf hy hulle feitlik deurgaans aan Baruk toe. Die verskil in formulering laat dink dat 46:13 en 50:1 dalk van 'n ander hand kan wees. Inderdaad wys Van Selms daarop dat 50-51 deur Jeremia self neergeskryf is (Van Selms 1974a: 72). Die ander opskrif, 46:13, staan by 'n profesie wat deur Van Selms teen 601 gedateer word (Van Selms 1974b: 20), in 'n tyd dus toe Baruk reeds 'n paar jaar as skrywer vir Jeremia opgetree het (Van Selms 1974a: 90). Hier kan ons dus net by die vermoede bly dat hier ' $n$ ander hand werksaam was. Dat die opskrif in 50:1 self ook van Jeremia afkomstig is, lyk waarskynlik alleen indien die laaste deel daarvan wel 'n toevoeging is (Van Selms 1974b: 54). Dit val op dat die ander formule, ${ }^{\star}$ šer hâa $\bar{a}{ }^{\circ} e l$, die voorkeur geniet in die perikoopopskrifte.

In opskrifte tref ons dié formule slegs aan by die d'bar yhwh-opskrifte, en by die haddäbär-opskrifte hier in Jeremia. Kyk ons dan na die 
voorkoms van hyh saam met $d \bar{a} b \bar{a} r$, tref dit dat wat die profete betref, dié verbinding nie voorkom in vooreksiliese boeke nie, maar wel volop in Jeremia en Esegiël, en ook in die na-eksiliese boeke, Haggai en Sagaria. Buite die profeteboeke is die verbinding skaars. Ons vind in 2 Samuel 24:11; 1 Konings 16:7; 18:1, 31 en 2 Konings 20:4 die uitdrukking hâya d'bar-yhwh 'el (soms in ander volgorde) en dan ook nog in Genesis 15:1, maar daar gevolg deur bammah $h^{a} z \bar{e}$. Verder vind ons way'h $\bar{\imath}$ $d^{e}$ bar-yhwh ' $\mathrm{el}$ in 1 Samuel 15:10; 2 Samuel 7:4; 1 Konings 6:11; 12:22; $13: 20 ; 16: 1 ; 17: 2,8 ; 21: 17,28$ en Jesaja 38:4. Albei vorms kom dan ook nog enkele kere voor in Daniël, Jona en Kronieke. Genesis 15:1-6 word deur talle geleerdes in die later koningstyd gedateer, dit is in die tyd toe die deuteronomis aan die werk was (Westermann 1981: 254, $256 \mathrm{vv}$ ). Wat Westermann oor die voorkoms van die uitdrukking sê, het egter nader kwalifikasie nodig. Dit veronderstel nie net 'die profesie' nie (Westermann 1981: 257), maar 'n spesifieke stadium in die denke oor en formulering van die profetiese openbaringsontvangs. 'n mens kan die vermoede nie ontwyk nie dat Baruk, as dit inderdaad hy is wat verantwoordelik is vir die perikoopopskrifte in Jeremia, tuis was in die deuteronomistiese skool. As hy die ontwerper was van dié besondere, teologies diep deurdagte perikoopopskrifte, sou hy dan nie ook verantwoordelik kon wees vir die opskrifte van die ander profeteboeke wat dieselfde relatiefsin het nie? Dit word nog meer waarskynlik as die Septuagint-opskrif in Jeremia 1:1 'n verbetering van hom was ter vervanging van die ouer dibrế-opskrif. Dan is die verhouding tussen die Septuagint-resensie en die Masoretiese resensie egter meer gekompliseerd as in die hipotese van Van Selms. Voorlopig wil ek die standpunt handhaaf wat ek in 1972 uitgespreek het, naamlik dat net soos in die geval van Amos, Jeremia se uitsprake die dibrẹ-opskrif gekry het omdat hulle aanvanklik nie aanvaar is as egte Jahwe-woorde nie. Die grammatikaal uitsonderlike konstruksie in 1:2 is 'n aanduiding dat Baruk moeite gehad het om op 1:1 'n sin te laat volg wat die gesag van die Jeremia-woorde by voorbaat duidelik sou stel.

Onvermydelik gaan 'n beskouing van die opskrifte gepaard met spekulasie. Tog het dit sin om hulle geïsoleerd te bekyk en vrae te stel oor hulle vorm. Ons het hier immers te doen met aanwysers vir die voorgeskiedenis van die kanon.

\section{Literatuurverwysings}

OBERHOLZER, JP [1978]. Die opskrifte in die profeteboeke I. HTS 34/4, 70-80. 
VAN DER WOUDE, AS 1976. Micha. Nijkerk: Callenbach. (De Prediking van het Oude Testament.)

VAN SELMS, A 1972. Jeremia, Deel I. Nijkerk: Callenbach. (De Prediking van het Oude Testament).

VAN SELMS, A 1974a. Jeremia, Deel II. Nijkerk: Callenbach. (De Prediking van het Oude Testament).

VAN SELMS, A 1974b. Jeremia, Deel III en Klaagliederen. (De Prediking van het Oude Testament).

WESTERMANN, C 1981. Genesis, Teilband Zwei. Genesis 12-36. Neukirchen-Vluyn: Neukirchener Verlag. (BK.AT).

ZIMMERLI, W 1969. Ezechiel, Teilband I. Neukirchen-Vluyn: Neukirchener Verlag. (BK.AT). 